\title{
USING MOBILE LEARNING AND RESEARCH BASED LEARNING TO ATTRACT STUDENTS INTO QUANTUM INFORMATION RESEARCH
}

\author{
Francisco Javier Delgado-Cepeda and Marco Benjamín Enríquez-Flores \\ Tecnologico de Monterrey, Engineering and Science School \\ Carretera a Lago de Guadalupe km. 3.5, Atizapán, Estado de Mexico, CP. 52926, Mexico
}

\begin{abstract}
Research-Based Learning seeks a new valued perception of scientific research through its inclusion in educative spaces. Mobile Learning promotes the inclusion of different terrains of university education. Research is not an exception. This work presents an initiative to include undergraduate and graduate students in Quantum Information research assisted by a mobile site to learn and collaborate. We analyse the performance in terms of participants, impact factor and scientific collaborations based on analytics included in the site, tracking the participants in their different inclusion spaces.
\end{abstract}

\section{KEYWORDS}

Mobile Learning, Education for Research, Educational Innovation, Quantum Information, Higher Education

\section{INTRODUCTION}

Nowadays, education has become increasingly oriented to satisfy the immediate human resources necessities in the industry (Kromydas, 2017). Oriented mainly to develop concrete competencies to occupy workplaces in the industry (Corominas, Canals and Villar, 2010). Under this landscape, the former wider vision of university has been overshadowed to be oriented to the masses. On this role, the mobile learning revolution has been mainly exploited to reach different types of education, technical or university inclusive (Wade, 2014), with outstanding examples of deeper education experiences (Hosler, 2014). Nevertheless, it has been expressed also about the absence of educative spaces to develop innovation, original knowledge and research competencies (Healey, 2005), thus boosting initiatives to overcome such deficiencies - STEM education or education oriented to the future- (Prager and Omenn, 1980). Universities have recovered such spaces (West, 2000) modelling the contemporary University behaviour.

The aim of this work is to bring a reflexive assessment of mobile learning as a companion element in education for research, concretely in the Quantum information (QI) trend. We show their evolution becoming a useful and effective resource to attract engineering and science students on this still new technological area. The second section depicts the entire project and it concretes the research objectives. The third section presents the evolution in terms of the attraction of students. The fourth section states the main findings and the discussion. The last section states the conclusions and the future development for the education initiative.

\section{RESEARCH-BASED LEARNING AND MOBILE LEARNING}

Quantum Information area in the modern era and its education necessities are raising in a traditional educative scenario (EU, 2016). Just in the 21st century they are generating the majority of their non-conventional technological proposals. However, those areas have not been completely settled in the curricula for electronic, mechatronics, nanotechnology, chemistry or computer engineering among others.

The initiative from the Quantum Information Processing Group (QIPG) has been developed to show and to attract students into scientific and technical research (Delgado, 2018a). It includes participation in seminars, a yearly workshop in QI, a formal topic in Quantum computation for undergraduate students, 
research stays of students in the QIPG and formal work with graduate students (thesis and scientific papers). The entire initiative have been managed as Research-Based Learning (RBL) (Barnett, 1992). Despite the model has been sustained by a few years, it has become a basis for development of research human resources.

Mobile learning has been an important element in the attraction. We prepare the main development to extensively cover different areas of attraction, education and research with students through several levels: Tangle (Delgado, 2018b), including a series of learning modules as MOOC's and MOOR's. They are reconfigurable for several approaches, depth levels and profiles: scientific, engineering and computational. In addition, our university created five years ago, a yearly space of one week for innovation and research, Semana I (from the Spanish of Innovation week), where students enrol in one from lots of activities associated with research, entrepreneurship, design, etc. projects. There, QIPG has created a yearly Quantum Information Workshop for undergraduate students (Delgado, 2018a) with Tangle, showing its usefulness to improve knowledge and performance in the second week, a face-to-face section (Delgado, 2018b).

Is the use of mobile learning technologies useful to improve the impact on the research production in academic spaces oriented to research? We are integrating the whole outcomes with a scope of education based on research within a mobile learning basis, thus the current objectives for this report are:

1) To stratify the attraction of human resources in the entire project with the scientific production generated

2) To evaluate the impact of mobile learning in terms of time, human resources and scientific products

The research is based on outcomes of production and the analytics raised through four years development (Delgado, 2018a, 2018b). Despite, the current report will include entire sets covering not only the yearly workshop: seminars, the research stays (one-year participation in an own project having as a mandatory outcome the publication of a scientific paper) and the graduate thesis and their associated products.

\section{FIGURES AND OUTCOMES OF QIPG INITIATIVE}

We are interested in the analysis of students' inclusion in the research group covering the first objective. Identification becomes useful to track analysis patterns related to mobile learning and mobile collaboration strategies. We report first the conformation of layers and the relation with students participating in research. The information from other analytics included in Tangle let to understand the whole picture of interactions in a quantitative approach given by the time usage, the number of collaborations and the scientific products.

\subsection{Stratification in the Involvement of Participants}

Figure 1 depicts the human resources involved and developed with scientific products. Figure 1a shows the layers of the impact of those initiatives. Straight lines depict the inner and deeper involvement.

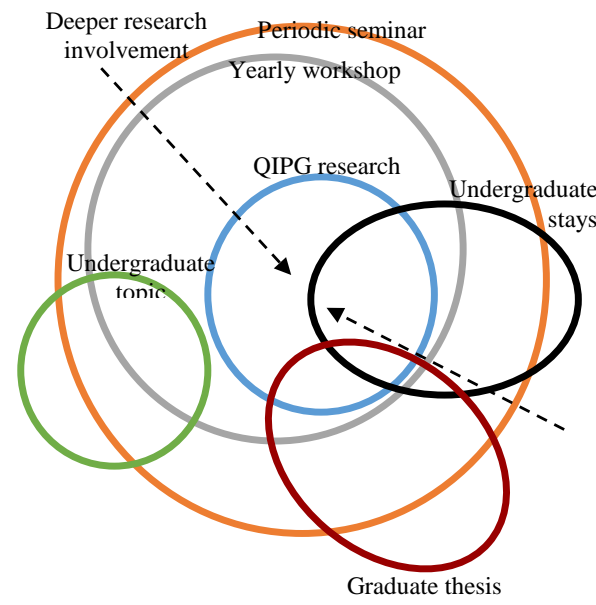

a)

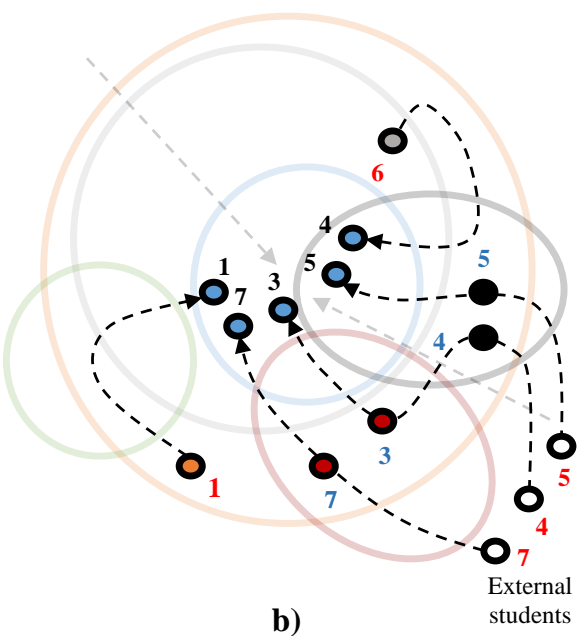

b)

Figure 1. a) Group layers to arrive into the research projects, and b) paths of development into real research from initial students (red), intermediate students through the layers (blue) to finally concreting indexed research papers (black) 
Several groups have had a deeper interaction with the researchers in QIPG collaborating in research. From the undergraduate level, the periodic seminar, and the QI workshop are the first contact point before the arrival of the research activities. Some students go through the undergraduate research stays first, others go to graduate studies in nanotech, computer science or engineering whose cloisters QIPG belongs. Some students are totally external ones arriving directly to graduate studies. Figure $1 \mathrm{~b}$ depicts the paths followed until now together with the final research works being concreted after those relations (blue dots with the numbers in black). Identified tracks are shown with dashed curves going through different groups or activities. All tracks are departing from coloured points (marked with red numbers indicating the number of students) in agreement with their origin group crossing secondary dots through their transiting membership group.

The layers of the students' arrival have been constructed on the time as QIPG strategies generated through the politics and spaces settled and allowed by our institution. Despite, they have been generated good results in terms of students' attraction and scientific production.

\subsection{Mobile Learning Impact in Learning and Scientific Production}

The use of learning analytics (Greller and Drachsler, 2012) through Tangle tool permitted to follow the advance of learning for the different groups and students (Delgado, 2018b). Particularly, during the yearly workshop, the interaction has been intensively measured inside Tangle. Workshop has become the main attraction boosting deeper collaboration with QIPG. Demographics between 2017 and 2018 are in Table 1.

Table 1. Demographics of the three cohorts in the yearly workshop in Quantum information

\begin{tabular}{|c|c|c|c|c|c|c|c|c|c|}
\hline \multirow{4}{*}{ GENDER } & Year & \multicolumn{4}{|c|}{ Female } & \multicolumn{4}{|c|}{ Male } \\
\hline & 2017 & \multicolumn{4}{|c|}{3} & \multicolumn{4}{|c|}{22} \\
\hline & 2018 & \multicolumn{4}{|c|}{6} & \multicolumn{4}{|c|}{22} \\
\hline & 2019 & \multicolumn{4}{|c|}{1} & \multicolumn{4}{|c|}{26} \\
\hline \multirow{4}{*}{ PROGRAM } & Year & \multicolumn{3}{|c|}{ Engineering } & \multicolumn{3}{|c|}{ Computer science } & \multicolumn{2}{|c|}{ Physics } \\
\hline & 2017 & \multicolumn{3}{|c|}{10} & \multicolumn{3}{|c|}{11} & \multicolumn{2}{|c|}{4} \\
\hline & 2018 & \multicolumn{3}{|c|}{10} & \multicolumn{3}{|c|}{13} & \multicolumn{2}{|c|}{5} \\
\hline & 2019 & \multicolumn{3}{|c|}{5} & \multicolumn{3}{|c|}{10} & \multicolumn{2}{|c|}{12} \\
\hline \multirow{4}{*}{ SEMESTER } & Year & $2^{\text {nd }}$ & $3^{\text {rd }}$ & $4^{\text {th }}$ & $5^{\text {th }}$ & $6^{\text {th }}$ & $7^{\text {th }}$ & $8^{\text {th }}$ & $9^{\text {th }}$ \\
\hline & 2017 & 4 & 7 & 4 & 2 & 2 & 2 & 2 & 2 \\
\hline & 2018 & 4 & 9 & 5 & 0 & 0 & 0 & 5 & 0 \\
\hline & 2019 & 2 & 7 & 7 & 4 & 0 & 1 & 0 & 4 \\
\hline \multirow{4}{*}{ ORIGIN } & Year & \multicolumn{4}{|c|}{ Local (Mexico City) } & \multicolumn{4}{|c|}{ Non-local } \\
\hline & 2017 & \multicolumn{4}{|c|}{14} & \multicolumn{4}{|c|}{11} \\
\hline & 2018 & \multicolumn{4}{|c|}{14} & \multicolumn{4}{|c|}{14} \\
\hline & 2019 & \multicolumn{4}{|c|}{14} & \multicolumn{4}{|c|}{13} \\
\hline
\end{tabular}

Despite, in the current analysis, we are not interested particularly in the local impact on the workshop. We analyse the relation of mobile interactions with the final research product years ago. Here, previous research has shown a meaningful impact of the blended learning scheme on the learning effectivity (Delgado, 2018b).

Analytics in Tangle have tracked the entire process by participant through the learning, collaboration and writing processes. We set the maximum number of interactions as 1 in a scale from 0 to 1 where 0 is any register of use. Mapping the whole path followed by each participant during the interaction, gathering each collaboration of any participant with another in each paper published and tracking if it was published in indexed or Conference journals, we set the Figure 2 including such relations and quantitative tracking. Each participant in Figure 1 was mapped in Figure 2 which is a data mining graph including statistical information. Three main points should boost the reading of graph: the three dots reporting the scientific articles published in indexed journals (red for a graduate project and yellow otherwise) or in conference proceedings (pink for undergraduate projects). Each publication is connected with dashed lines to blue dots (final stages of publication of each participant). Nodes of the graph are coloured as in Figure 1 for the several stages of each student. A solid red line implies a collaboration co-authoring certain paper (undergraduates collaborating with graduates). Colour scale reports the level of usage of Tangle in the scale depicted. White, grey and orange nodes are the beginning path of each student. Solid grey lines join the same type of such departing nodes as reference. ES and IS state external and internal students respectively, and US and GS for 
undergraduate and graduate studies respectively. Thus, eleven master and doctoral degrees thesis have generated scientific papers published in indexed journals and nine conference papers (SCOPUS). Use of Tangle appears in the upper range (0.5-1.0), Figure 2.

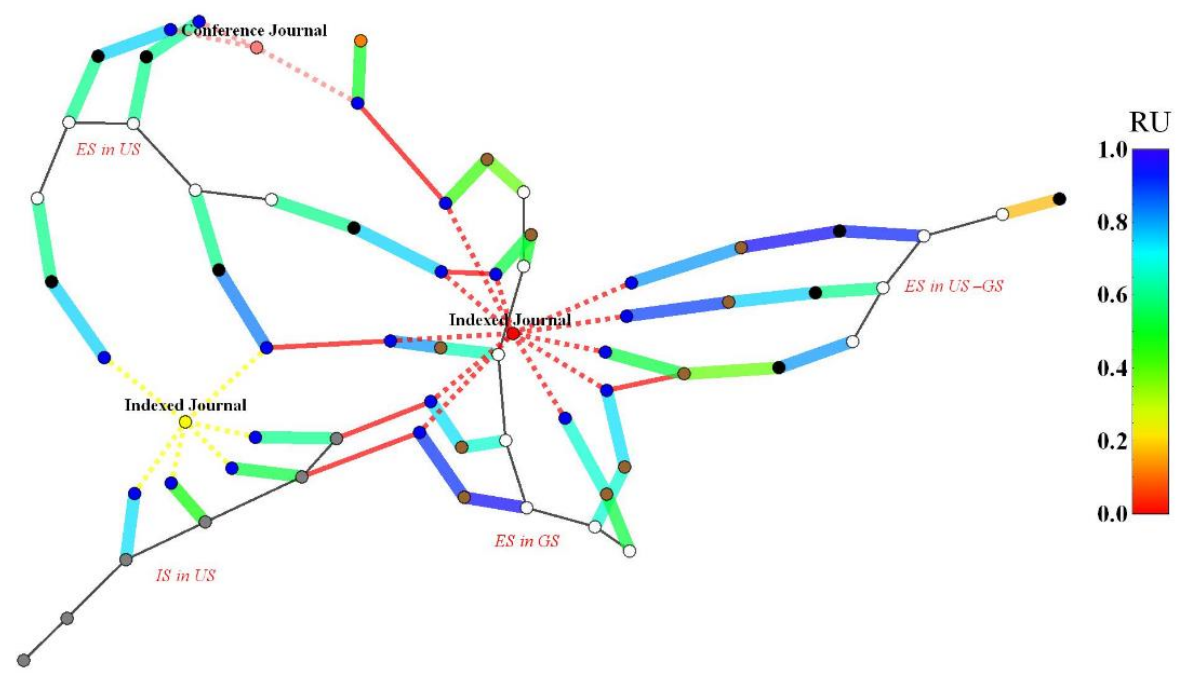

Figure 2. Interaction among students publishing in indexed (red: graduate, yellow: undergraduate) or conference (pink: undergraduate) journals with relative usage of Tangle (bar: 0-no usage, 1-max usage). Solid red lines set collaborations

To verify a possible relationship within groups, we split the group in three as function of the number of periods belonging to QIPG $(1,2,3)$, averaging the Tangle level of use. Then, we run a one-factor ANOVA test with $p=0.05$ between groups related with the usage level of the tool. Results are in the Table 2 . Test does not give sufficient statistical evidence about meaningful difference among groups $(p=0.062>0.05)$ despite averages in Table 2 suggest it. Because populations with collaborations are small, there is no possibility to compare the level of use having or not having collaborations. In the future, this is an important aspect to evaluate as assessment of performance for Tangle as a boosting tool of such scientific collaborations.

Table 2. ANOVA for Tangle usage among students staying a different number of stages in QIPG

\begin{tabular}{|c|c|c|c|c|c|c|}
\hline Groups & Sample & & Sum & \multicolumn{2}{|c|}{ Average } & Variance \\
\hline 1 & 6 & & 2.110 & \multicolumn{2}{|c|}{0.352} & 0.018 \\
\hline 2 & 12 & & 5.575 & \multicolumn{2}{|c|}{0.465} & 0.008 \\
\hline 3 & 3 & & 1.560 & \multicolumn{2}{|c|}{0.520} & 0.013 \\
\hline Source & S.S. & d.f. & M.S. & $F_{\text {calc }}$ & p-value & $F_{\text {critical }}$ \\
\hline Between & 0.073 & 2 & 0.037 & 3.263 & 0.062 & 3.555 \\
\hline Within & 0.202 & 18 & 0.011 & & & \\
\hline Total & 0.275 & 20 & & & & \\
\hline
\end{tabular}

Finally, we compare the averages of impact factor and time of the development of scientific products. Figure 3 shows the 2017 (Green), 2018 (Cyan) and 2019 (Blue) productions. Size dot shows the average number of collaborations by article, ranging from 1.66 to 1.25 . Reduction exhibits growing independence of undergraduates in research. The plot shows an increasing quality and a decreasing time of development.

\section{CONCLUSIONS}

Research has gained terrain in the aspirations of university students since several years ago (Banner and Bennet, 1999). While, society has been modifying their perception of the value of research as an activity bringing welfare. Quantum Information is still a relatively emerging field of research, but rapidly including a growing number of professionals collaborating to enrich the potential of such research area. 
In the report, RBL has become an innovative action to attract students in the field settled in different spaces let by our university. The use of a Mobile strategy to teach, discuss and collaborate the research topics was central. Both initiatives have been harmonically combined showing a real increase in the number of students involved, the number of publications generated, and in the impact factor. Collaborations in quality and number should be evaluated in the next years when more students will be participating in our group. Those outcomes have begun to position QIPG in the world research landscape of Quantum Information.

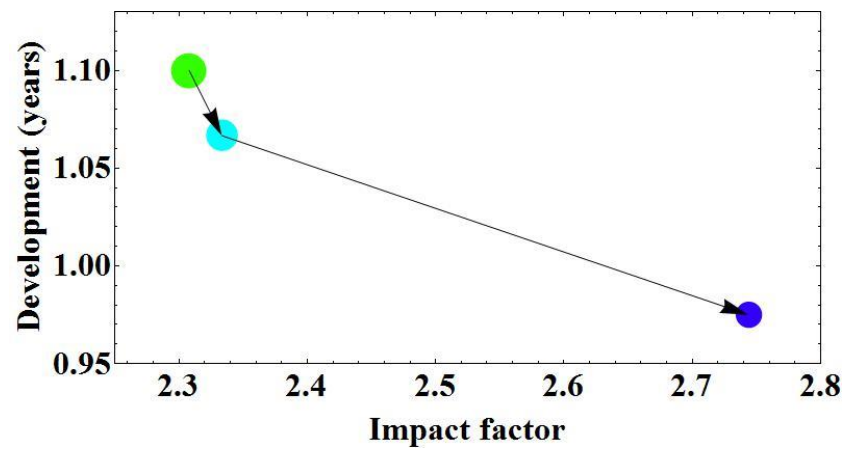

Figure 3. Average time of development versus average impact factor through 2017 (Green), 2018 (Cyan) and 2019

(Blue). Point size reflects the average number of students by scientific product in a range from 1.66 to 1.25

\section{ACKNOWLEDGEMENT}

The authors would like to acknowledge the financial and the technical support of Writing Lab, TecLabs, Tecnologico de Monterrey, Mexico, in the production of this work.

\section{REFERENCES}

Bauer, K. and Bennet, J. 1999. Alumni Perceptions Used to Assess Undergraduate Research Experience. The University of Delaware. Retrieved form: http://www1.udel.edu/RAIRE/Alumniper.pdf

Barnett, R. 1992. Linking teaching and research: A critical inquiry. The Journal of Higher Education Vol. 63, No. 6; ProQuest Education Journals, pp. 619-623.

Corominas, E., Canals, C. and Villar, E. 2010. The match between university education and graduate labour market outcomes. AQU: Catalunya, Spain.

Delgado, F. 2018. A learning challenge for a multidisciplinary quantum information and quantum processing workshop during "Semana I". Proceedings of INTED 2018.

Delgado, F. 2018. Blended learning in research oriented education: TANGLE, an educative suite for quantum information. IADIS International Journal on WWW/Internet Vol. 16, No. 1. ISSN: 1645-7641.

EU. 2016. Quantum Manifesto: A new era of technology. European Union. Retrieved from: http://horizon2020.mon. bg/en?h=downloadFile \&fileId $=86$

Greller, W.; Drachsler, H. 2012. Translating Learning into Numbers: Toward a Generic Framework for Learning Analytics. Educational Technology and Society. 15 (3), pp. $42-57$.

Healey, M. 2005. Linking research and teaching to benefit student learning. Journal of Geography in Higher Education, 29(2), pp. 183-201.

Hosler, A. 2014. Massive Open Online Research: The MOOC Evolves into the MOOR. Retrieved from: http://www. emergingedtech.com/2014/01/massive-open-online-research-the-mooc-evolves-into-the-moor/EmergingEdTech

Kromydas, T. 2017. Rethinking higher education and its relationship with social inequalities: past knowledge, present state and future potential. Palgrave Communications Vol. 3, No. 1, pp. 1-12.

Prager, D. and Omenn, G. 1980. Research, innovation, and university-industry linkages. Science Vol. 207, No. 4429, pp. 379-384.

Wade, G. 2014. New model needed to close widening education gap. University World News 334. Retrieved from: http://www.universityworldnews.com/article.php?story=20141121091229767

West, J. 2000. Higher education and employment: opportunities and limitations in the formation of skills in a mass higher education system, Journal of Vocational Education and Training Vol. 52, No. 4, pp. 573-588. 